\title{
Electron properties and air mixing in radio frequency driven argon plasma jets at atmospheric pressure
}

\section{Citation for published version (APA):}

Gessel, van, A. F. H., Brandenburg, R., \& Bruggeman, P. J. (2013). Electron properties and air mixing in radio frequency driven argon plasma jets at atmospheric pressure. Applied Physics Letters, 103, 064103-1/5. https://doi.org/10.1063/1.4817936

DOI:

$10.1063 / 1.4817936$

Document status and date:

Published: 01/01/2013

\section{Document Version:}

Publisher's PDF, also known as Version of Record (includes final page, issue and volume numbers)

\section{Please check the document version of this publication:}

- A submitted manuscript is the version of the article upon submission and before peer-review. There can be important differences between the submitted version and the official published version of record. People interested in the research are advised to contact the author for the final version of the publication, or visit the $\mathrm{DOI}$ to the publisher's website.

- The final author version and the galley proof are versions of the publication after peer review.

- The final published version features the final layout of the paper including the volume, issue and page numbers.

Link to publication

\section{General rights}

Copyright and moral rights for the publications made accessible in the public portal are retained by the authors and/or other copyright owners and it is a condition of accessing publications that users recognise and abide by the legal requirements associated with these rights.

- Users may download and print one copy of any publication from the public portal for the purpose of private study or research.

- You may not further distribute the material or use it for any profit-making activity or commercial gain

- You may freely distribute the URL identifying the publication in the public portal.

If the publication is distributed under the terms of Article 25fa of the Dutch Copyright Act, indicated by the "Taverne" license above, please follow below link for the End User Agreement:

www.tue.nl/taverne

Take down policy

If you believe that this document breaches copyright please contact us at:

openaccess@tue.nl

providing details and we will investigate your claim. 


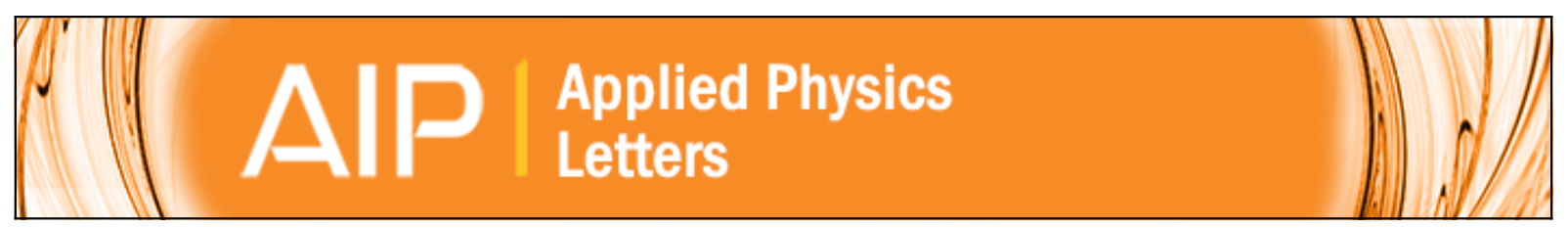

\section{Electron properties and air mixing in radio frequency driven argon plasma jets at atmospheric pressure}

Bram van Gessel, Ronny Brandenburg, and Peter Bruggeman

Citation: Applied Physics Letters 103, 064103 (2013); doi: 10.1063/1.4817936

View online: http://dx.doi.org/10.1063/1.4817936

View Table of Contents: http://scitation.aip.org/content/aip/journal/apl/103/6?ver=pdfcov

Published by the AIP Publishing

\section{Articles you may be interested in}

Characteristics of atmospheric-pressure non-thermal N2 and N2/O2 gas mixture plasma jet

J. Appl. Phys. 115, 033303 (2014); 10.1063/1.4862304

Effects of water addition on $\mathrm{OH}$ radical generation and plasma properties in an atmospheric argon microwave plasma jet

J. Appl. Phys. 110, 053304 (2011); 10.1063/1.3632970

Stark broadening measurement of the electron density in an atmospheric pressure argon plasma jet with doublepower electrodes

J. Appl. Phys. 107, 063303 (2010); 10.1063/1.3330717

Optical and electrical characterization of an atmospheric pressure microplasma jet for $\operatorname{Ar} \mathrm{C} \mathrm{H} 4$ and $\operatorname{Ar} \mathrm{C} 2 \mathrm{H} 2$ mixtures

J. Appl. Phys. 101, 103307 (2007); 10.1063/1.2714646

Control of radio-frequency atmospheric pressure argon plasma characteristics by helium gas mixing

Phys. Plasmas 13, 013504 (2006); 10.1063/1.2161173

\section{A|P $\left.\right|_{\text {Applied Physics }} ^{\text {Journal of }}$}

Journal of Applied Physics is pleased to announce André Anders as its new Editor-in-Chief 


\title{
Electron properties and air mixing in radio frequency driven argon plasma jets at atmospheric pressure
}

\author{
Bram van Gessel, ${ }^{1}$ Ronny Brandenburg, ${ }^{1,2}$ and Peter Bruggeman ${ }^{1, a)}$ \\ ${ }^{1}$ Department of Applied Physics, Eindhoven University of Technology, PO Box 513, 5600 MB Eindhoven, \\ The Netherlands \\ ${ }^{2}$ Leibniz Institute for Plasma Science and Technology (INP Greifswald), Felix-Hausdorff-Str. 2, \\ D-17489 Greifswald, Germany
}

(Received 3 May 2013; accepted 23 July 2013; published online 8 August 2013)

\begin{abstract}
A time modulated radio frequency (RF) plasma jet operated with an Ar mixture is investigated by measuring the electron density and electron temperature using Thomson scattering. The measurements have been performed spatially resolved for two different electrode configurations and as a function of the plasma dissipated power and air concentration admixed to the Ar. Time resolved measurements of electron densities and temperatures during the RF cycle and after plasma power switch-off are presented. Furthermore, the influence of the plasma on the air entrainment into the effluent is studied using Raman scattering. (C) 2013 AIP Publishing LLC. [http://dx.doi.org/10.1063/1.4817936]
\end{abstract}

Cold atmospheric plasma jets are of increasing interest for a large range of applications, ranging from surface treatment, plasma chemical conversion to biomedical applications. ${ }^{1}$ These plasmas have a rich chemistry driven by the electrons. Often the plasma jets are generated in noble gases (Ar or He) with small molecular admixtures and operated in open air. Especially the air-related species (such as $\mathrm{O}, \mathrm{N}, \mathrm{O}_{3}$, $\mathrm{OH}$, and NO) are of key importance to many applications. For the development and optimization of these applications, it is therefore of crucial importance to study and quantify the electron properties and air distribution in these plasmas. In this contribution, we present the first spatially and temporally resolved direct measurements of electron density $n_{e}$, electron temperature $T_{e}$, and air density $\left(n_{\mathrm{N}_{2}}\right.$ and $\left.n_{\mathrm{O}_{2}}\right)$ in an argon jet. $n_{e}$ and $T_{e}$ are investigated by means of Thomson scattering. The air density is studied using Raman scattering. After a brief section on the experimental setup, our experimental results are presented, followed by a discussion which includes a comparison with related work.

The used plasma source is identical to the one in Ref. 2 . It consists of a pin electrode placed inside a quartz tube ending in open air. For the grounded electrode, two configurations are used: a ring around the tube or a plate in the jet effluent (see also Figure 3 ). Through the tube, there is a gas flow of $1.0 \mathrm{slm}$ Ar with a few percent of admixed air, $\mathrm{N}_{2}$ or $\mathrm{O}_{2}$. The pin electrode is powered with a radio frequency (RF) of $14.5 \mathrm{MHz}$ modulated with a $20 \mathrm{kHz}$ square pulse with a $20 \%$ duty cycle, such that the plasma is $10 \mu$ s on and $40 \mu \mathrm{s}$ off. The power dissipated by the plasma is measured using the method described by Hofmann et al. ${ }^{3}$

The Thomson and Raman scattering setup has been described in detail in our previous work. ${ }^{4}$ See also this work for a schematic overview of the setup. The diagnostics setup is identical, except that the iCCD camera has been replaced (Andor iStar734), which improved the sensitivity by approximately a factor 10 . The scattering spectrum is measured spatially resolved with a resolution of about $50 \mu \mathrm{m}$ along the laser beam. An example of a measured spectrum is shown in

${ }^{\text {a)} E l e c t r o n i c ~ m a i l: ~ p . j . b r u g g e m a n @ t u e . n l ~}$
Figure 1. The spectrum (with the signals from stray light and Rayleigh scattering removed) consists of Raman $\left(\mathrm{N}_{2}\right.$ and $\left.\mathrm{O}_{2}\right)$ and Thomson scattering signals. The separation is performed using a fitting method, ${ }^{4}$ which enables the determination of the $n_{e}, T_{e}$ and the densities $n_{\mathrm{N}_{2}}$ and $n_{\mathrm{O}_{2}}$.

The measured densities are absolutely calibrated by the Raman signal of ambient air at room temperature. Axial profiles of the plasma jet are obtained by moving the jet with respect to the laser beam using a motorized stage. The axial zero position is taken at the tube edge. The triggering of the laser and camera is synchronized with the plasma modulation.

In Figure 2, spatially resolved air densities are shown. The results are compared for the plasma on and off case, with the same flow and pre-mixed air concentration. In the center of the gas stream, near the tube end, the air concentration is approximately equal to the admixed amount of $2 \%$ $\left(4.9 \times 10^{23} \mathrm{~m}^{-3}\right)$. In the case of a plasma, the air concentration has a minimum of $1.6 \%$, with a fitted $\mathrm{N}_{2} / \mathrm{O}_{2}$ ratio of $81.2 \% / 18.8 \%$. This would indicate a dissociation degree of $\mathrm{O}_{2}$ and $\mathrm{N}_{2}$ of approximately $20 \%$. At higher axial positions and radially outward, the feed gas mixes with ambient air, causing an increase in the air concentration. In the plasma on case, compared to the plasma off case, significant air entrainment occurs at smaller distances. This suggests an increased mixing in case there is a plasma caused by increased turbulence due to heating of the gas (a maximum temperature of $480 \mathrm{~K}$ is measured $^{2}$ ) or possibly by electrohydrodynamic effects. ${ }^{5}$ The Reynolds number in the investigated jet for an argon flow of $1 \mathrm{slm}$ is approximately 1120. This means that inside the tube the flow is expected to be laminar ${ }^{6}$ but in the effluent turbulent structures may appear as a result of Kelvin-Helmholtz instabilities. ${ }^{7}$ These instabilities are caused by the shear forces at the interface of two gas flows with different velocities and possibly enhanced due to the increased temperature.

In the Thomson scattering measurements, the laser is triggered $9.0 \mu$ s after the start of the RF pulse (which has a total duration of $10 \mu \mathrm{s}$ ). At this time, the plasma is considered to be in steady state, as can be concluded from the time resolved Thomson scattering (see below). 


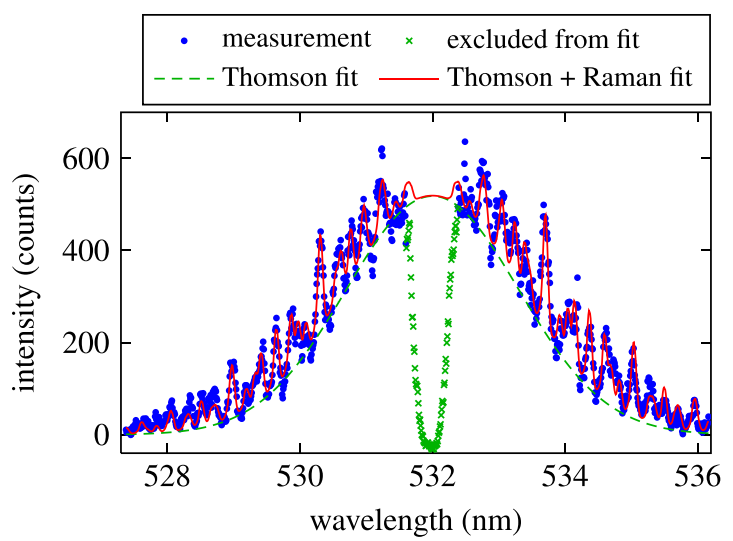

FIG. 1. Example of a fit of overlapping Thomson and Raman signals. The fitted parameters are $n_{e}=1.34 \times 10^{20} \mathrm{~m}^{-3}, \quad T_{e}=1.54 \mathrm{eV}$, $n_{\text {air }}=3.32 \times 10^{23} \mathrm{~m}^{-3}$, the fraction $n_{\mathrm{O}_{2}} / n_{\text {air }}=18.8 \%$, and $T_{\text {rot }}=382 \mathrm{~K}$. (Pin-plate geometry, $\mathrm{Ar}$ with $2.0 \%$ admixed air, $3.5 \mathrm{~W}$ plasma power, $0.5 \mathrm{~mm}$ axial position.)

To check for laser induced effects on the plasma, Thomson scattering measurements have been performed in similar plasma conditions with the laser energy varied between approximately 0.5 and $4 \mathrm{~mJ}$ per pulse (not shown). The obtained electron densities and temperatures match within $10 \%$, which is within the expected experimental error. Thus, laser heating as reported by Carbone et al. ${ }^{8}$ can be excluded for these conditions and we can consider the Thomson scattering measurements to be non-intrusive.

$2 \mathrm{D}$ profiles of the electron density, as obtained by Thomson scattering, are shown in Figure 3 for both electrode geometries. The maximum $n_{e}$ in case of the pin-plate arrangement is about one order of magnitude larger than for the pin-ring arrangement. Furthermore, in case of the pinplate the plasma is much longer and more contracted. This can be explained by the different field configurations. Note that for the pin-ring geometry a significant part of the power is dissipated between the needle and the ring inside the tube where is not measured. This restricts the power going into the jet effluent, thus, keeping $n_{e}$ outside the tube low. For the pin-plate geometry, the plasma channel is not perfectly straight, which had to be taken into account in the alignment of the laser focus point. To ensure that the measurements are performed in the center of the plasma jet, for each axial

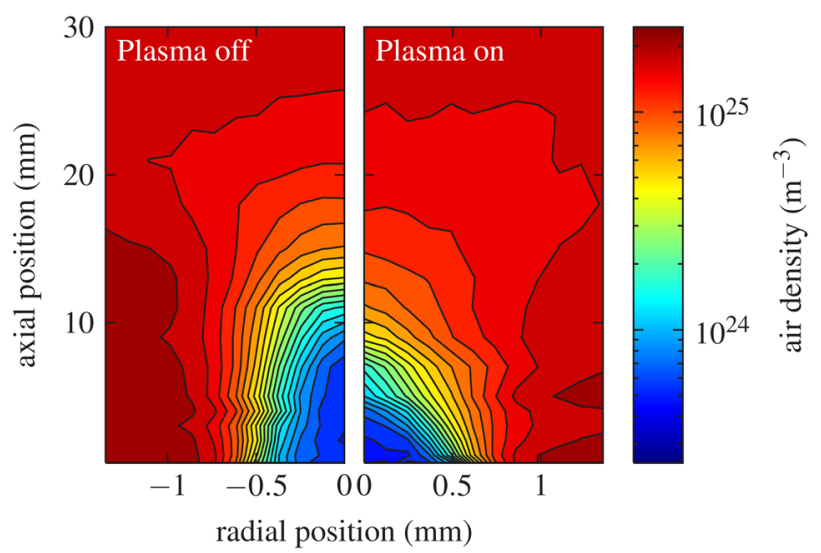

FIG. 2. 2D profile of the air density in the jet effluent. The plasma is operated using the pin-ring geometry, in Ar with $2.0 \%$ air and a power of $3.5 \mathrm{~W}$. Note the logarithmic color scale.
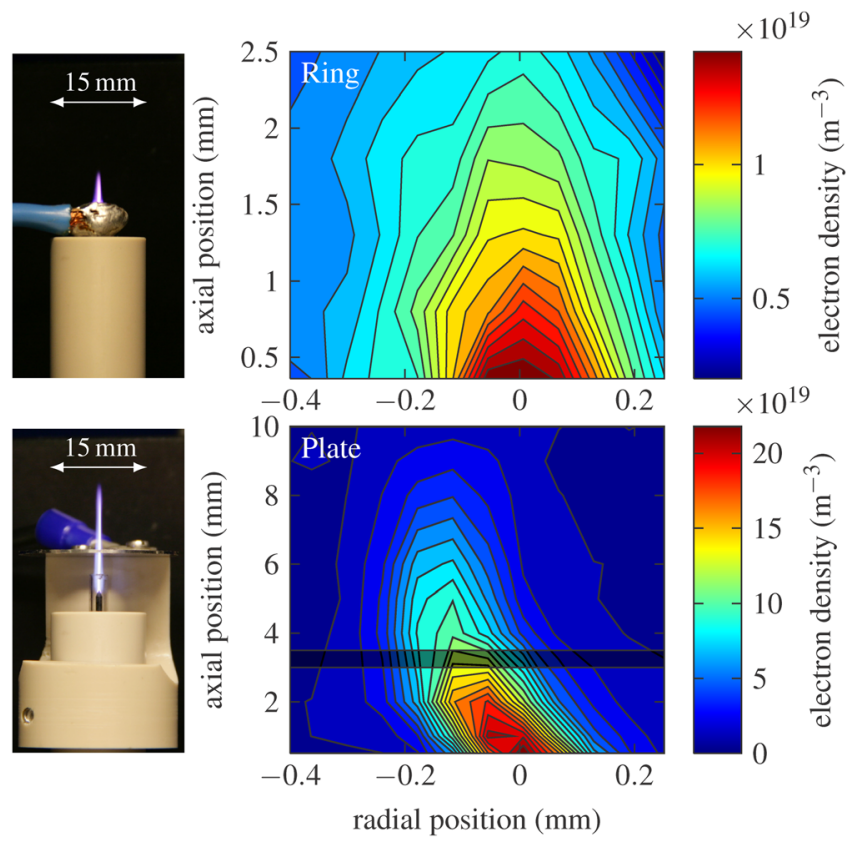

FIG. 3. 2D profiles of the electron density, measured at $9 \mu$ s from the start of the RF pulse. The jet is operated in Ar with $1.0 \%$ air, a power of $3.5 \mathrm{~W}$, and either the pin-ring (top) or the pin-plate (bottom) geometry. The dark rectangle indicates the position of the plate electrode. Note the difference in axial scale.

position, a radial scan is made to position the focus point of the laser at the maximum electron density.

Thomson scattering measurements are performed for different plasma conditions. The results of $n_{e}$ and $T_{e}$ with varying plasma dissipated power are shown for the case of the plate electrode in Figure 4. With increasing power $n_{e}$ increases, as expected. $T_{e}$ shows a slight decrease as function of power. However, the fitting procedure tends to overestimate $T_{e}$ in case the Thomson scattering signal is low compared to the Raman signal. ${ }^{4}$

In Figure $5, n_{e}$ and $T_{e}$ are shown for different concentrations of admixed air, $\mathrm{N}_{2}$ or $\mathrm{O}_{2}$ to the argon feed gas. In all cases, an increasing concentration of molecules causes a decrease of $n_{e}$. In the case of admixing $\mathrm{N}_{2}$ or air $T_{e}$ increases, but with the admixture of $\mathrm{O}_{2} T_{e}$ remains constant. From this, we can conclude that in case of admixed air the increase of $T_{e}$ is correlated mostly to the $\mathrm{N}_{2}$ admixture.

The delay between the triggering of the pulsed RF voltage, and the laser and the camera can be controlled with

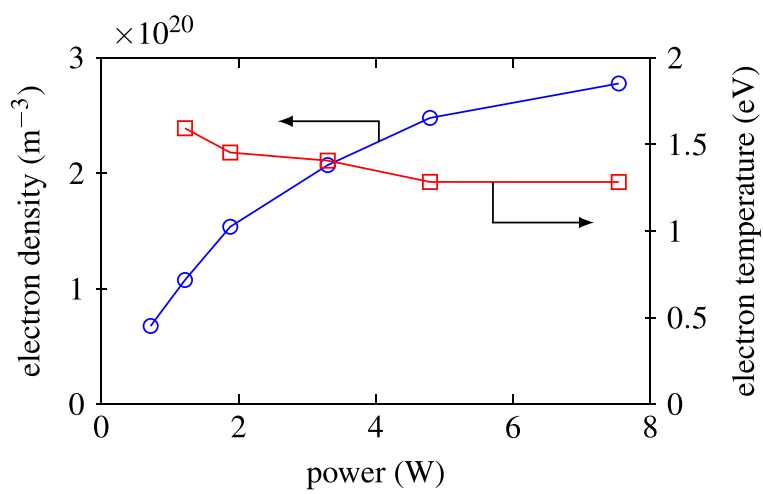

FIG. 4. Thomson scattering results as function of the plasma dissipated power (pin-plate geometry, Ar with $1.0 \%$ admixed air, $0.5 \mathrm{~mm}$ axial position, radially on-axis). 


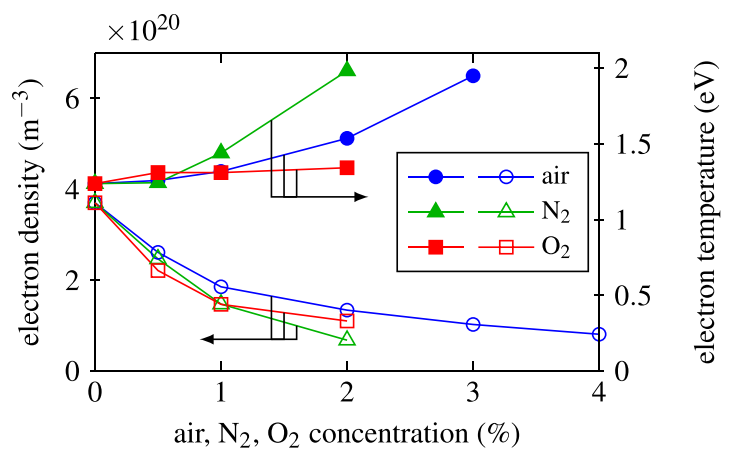

FIG. 5. Thomson scattering results as function of the amount of air, $\mathrm{N}_{2}$ or $\mathrm{O}_{2}$ admixed to the Ar flow. The plasma dissipated power is kept constant at $3.5 \pm 0.2 \mathrm{~W}$. (Pin-plate geometry, $0.5 \mathrm{~mm}$ axial position, radially on-axis.)

nanosecond accuracy. This allows for time resolved Thomson scattering measurements. The results of $n_{e}$ and $T_{e}$ during one $20 \mathrm{kHz}$ pulse are shown in Figure 6. Care has been taken that all measurements are done at the same phase of the $14.5 \mathrm{MHz}$ RF cycle.

After a delay of approximately $2 \mu \mathrm{s}$, a measurable Thomson signal appears and the electron density increases during a few microseconds. This shows that the plasma needs a few RF cycles to ignite and needs a few microseconds to reach a steady state. After the power is switched off $T_{e}$ and $n_{e}$ decrease. After approximately $1.5 \mu \mathrm{s}$, the Thomson signal has disappeared. Figure 7 illustrates that the high energy electrons disappear first, followed by the low energy electrons. As a result, $T_{e}$ reduces during the decay. This is in line with the example for low pressure plasmas by Ashida et $a l .{ }^{9}$ It needs to be emphasized that the RF power takes a few cycles to switch off, which makes it impossible to determine an accurate decay time of the electron density. The Thomson signals in Figure 7 are obtained by subtracting the Raman signal obtained during the plasma off phase from the measured Thomson/Raman signal. This was possible because the Raman signals are found to be constant during the $20 \mathrm{kHz}$ cycle.

In Figure 8, the Thomson scattering results are shown resolved for one $14.5 \mathrm{MHz} \mathrm{RF}$ cycle ( $68.8 \mathrm{~ns}$ period). It can be seen that $n_{e}$ is constant and that $T_{e}$ varies with the double of the RF frequency, in other words, the frequency of the electric field strength.

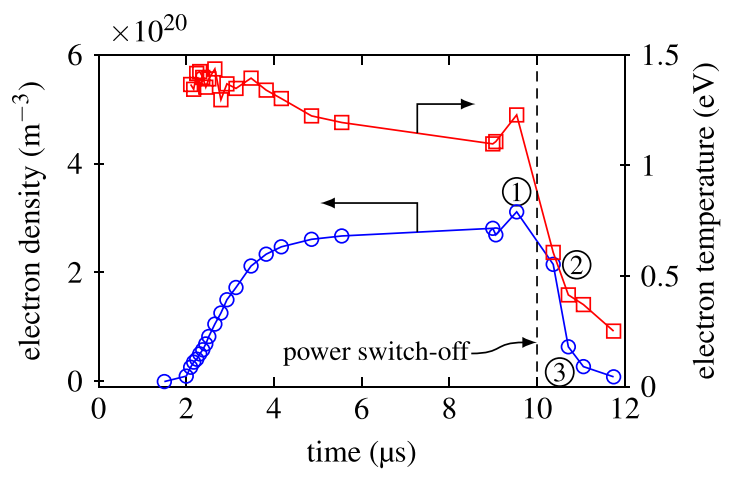

FIG. 6. Time evolution of the Thomson scattering signal during one cycle of the $20 \mathrm{kHz}$ pulse. The plasma on period is between 0 and $10 \mu \mathrm{s}$. (Pin-plate geometry, pure Ar flow, $3.5 \mathrm{~W}$ average plasma power, $0.5 \mathrm{~mm}$ axial position, radially on-axis.) The circled numbers in the image serve as a reference for Figure 7.

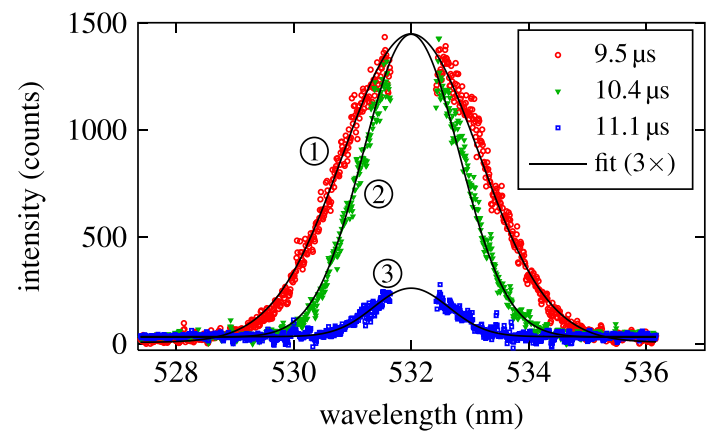

FIG. 7. Thomson scattering signals with Gaussian fit, during the decay phase of the electron density. The signals are corrected for Raman scattering and the central part of the spectrum is excluded. The fitted values of $n_{e}$ and $T_{e}$ are shown in Figure 6 at the corresponding circled numbers.

The error of the electron density measurements is estimated to be approximately $\pm 10 \%$ in the plasma center and slightly higher in the plasma edge regions where the Thomson signal decreases and the Raman signal increases. The electron temperatures have an estimated error of approximately $\pm 10 \%$ in the plasma center. These estimations are based on the accuracy of the fitting procedure and the signal to noise ratio. 4

Related work includes Balcon et al., ${ }^{10}$ who investigated pulsed RF driven discharges in a diffuse glow and filamentary mode at atmospheric pressure. The reported $n_{e}$ (and $T_{e}$ ) for both modes are $5 \times 10^{17} \mathrm{~m}^{-3}(1.3 \mathrm{eV})$ and $10^{21} \mathrm{~m}^{-3}$ $(1.7 \mathrm{eV})$, respectively. $n_{e}$ is estimated from line broadening and current density measurements, respectively, while $T_{e}$ is estimated from line intensity ratios. The $n_{e}$ of about $10^{18}$ $\mathrm{m}^{-3}$ for the diffuse mode has been confirmed in a later study by a line ratio measurement interpreted using a collisional radiative model. ${ }^{11}$ In the present experiment, the plasma in the pin-ring geometry is diffuse, with a structure in the center which resembles a contraction. In the case of the pin-plate geometry the plasma is more contracted. Densities within the above range are found at our conditions as well.

Hofmann et $a .^{3}$ have measured in a plasma jet similar to our case-using pure Ar, a pin-plate electrode geometry and the same power range - an $n_{e}$ of about $1-3 \times 10^{20} \mathrm{~m}^{-3}$. These results show excellent agreement with the independent measurements presented here. Schäfer et al. ${ }^{12}$ have measured $n_{e}$ and $T_{e}$ in a plasma filament in a RF plasma jet with $\mathrm{Ar}$

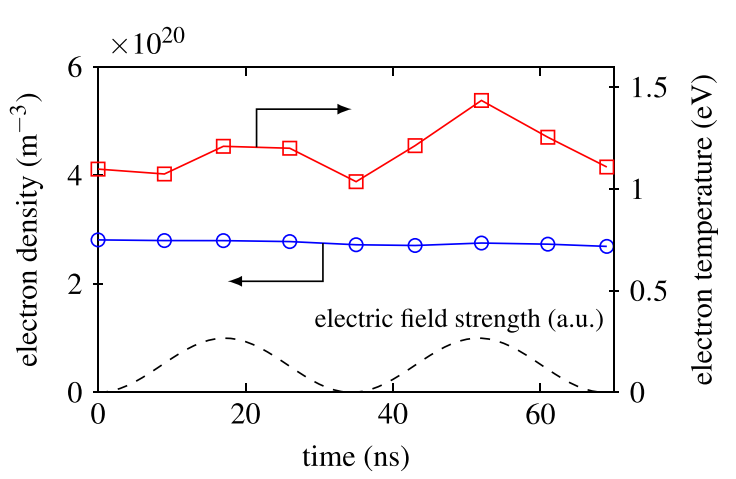

FIG. 8. Time evolution of the Thomson scattering signal during one 14.5 MHz RF cycle (pin-plate geometry, pure Ar flow, $0.5 \mathrm{~mm}$ axial position, $3.5 \mathrm{~W}$ plasma power). 
and compared to a fluid model of a single filament. The measurements indicate an $n_{e}$ in the range of $2.2-3.3 \times 10^{20}$ $\mathrm{m}^{-3}$ and $T_{e}$ of the order of $2-3 \mathrm{eV}$. The model predicts a density of $7 \times 10^{19} \mathrm{~m}^{-3}$ with $T_{e}=2.0 \mathrm{eV} . T_{e}$ obtained in the present work is at the lower limit of what is obtained in the work of Schäfer.

Diffuse atmospheric pressure Ar discharges have been modeled by Moravej et al. ${ }^{13}$ and they found for their conditions an $n_{e}=2 \times 10^{18} \mathrm{~m}^{-3}$ and $T_{e}=1.1 \mathrm{eV}$. Belostotskiy et al. ${ }^{14}$ measured $T_{e}$ and $n_{e}$ in the bulk of an atmospheric pressure DC microdischarge by Thomson scattering. The obtained values: $T_{e}=0.9 \pm 0.3 \mathrm{eV}$ and $n_{e}=6 \pm 3 \times 10^{19}$ $\mathrm{m}^{-3}$ have been found to correspond reasonably with a model, although the calculated $T_{e}$ is larger than the measured temperature. The discrepancy is explained by a small amount of highly energetic beam electrons emanating from the cathode sheath, which exist besides the bulk electrons as measured by Thomson scattering. The energetic electrons create an important non-local ionization source which is not included in the fluid model.

A potential underestimate of $T_{e}$ compared to the model of the plasma jet filament ${ }^{12}$ — assuming that the modeled conditions are representative for the current plasma source-can be explained by the electron energy distribution function (EEDF). The EEDF can be significantly non-Boltzmann and highly modulated in time. The ionization wave has a speed of approximately $10^{6} \mathrm{~ms}^{-1}$ (Ref. 2) which means that during the laser pulse of $5 \mathrm{~ns}$ the ionization front has moved a distance of about 50 times the beam waist of the laser. As a consequence, the major part of the electrons contributing to the Thomson scattering will be bulk electrons in the low electric field region behind the ionization front.

By the addition of air to Ar, the energy required to create one electron-ion pair will significantly increase due to additional electron energy losses in collisions leading to rotational and vibrational excitation of $\mathrm{O}_{2}$ and $\mathrm{N}_{2}$ (see, e.g., Lieberman ${ }^{15}$ ). In addition, electrons can also be lost faster through (dissociative) attachment to $\mathrm{O}_{2}$. At constant power, $n_{e}$ needs to decrease with increasing air concentration and/or $T_{e}$ needs to increase. Note that a global model of $\mathrm{Ar}-\mathrm{O}_{2}$ glow discharges at atmospheric pressure ${ }^{16}$ predicts a similar decrease in $n_{e}$ at constant power as found in the experiments, also with constant $T_{e}$ in the investigated range of $\mathrm{O}_{2}$ admixture. The significant increase in $T_{e}$ for $\mathrm{N}_{2}$ compared to $\mathrm{O}_{2}$ could be due to the higher ionization energy of $\mathrm{N}_{2}$ (which is similar to $\mathrm{Ar}$ ) compared to $\mathrm{O}_{2}$. In addition, there might be an effect of efficient vibrational energy losses in $\mathrm{N}_{2}$, however, a model is necessary to explain these differences in detail.

In conclusion, for the first time, values of $n_{e}$ and $T_{e}$ have been measured directly in an Ar-air non-equilibrium time modulated RF plasma jet at atmospheric pressure using Thomson scattering. The results show a good agreement with values in literature based on modeling and other diagnostics on similar plasmas. It was found that $n_{e}$ is significantly influenced by the geometry of the electrodes, which causes a diffuse or a filamentary discharge. Even with the same gas mixtures, flows and plasma dissipated power, differences in $n_{e}$ of more than a factor 10 are observed.

Using Raman scattering, an increased mixing of gas species was found in case the plasma is on, compared to the plasma off case. The dissociation degree for the investigated conditions is estimated to be approximately $20 \%$. Both the results on electron properties and air concentrations give valuable input for modeling of plasma jets for biomedical applications.

${ }^{1}$ M. Laroussi and T. Akan, Plasma Processes Polym. 4, 777 (2007).

${ }^{2}$ A. F. H. Van Gessel, K. M. J. Alards, and P. J. Bruggeman, J. Phys. D 46, 265202 (2013).

${ }^{3}$ S. Hofmann, A. F. H. van Gessel, T. Verreycken, and P. J. Bruggeman, Plasma Sources Sci. Technol. 20, 065010 (2011).

${ }^{4}$ A. F. H. Van Gessel, E. A. D. Carbone, P. J. Bruggeman, and J. J. A. M. van der Mullen, Plasma Sources Sci. Technol. 21, 015003 (2012).

${ }^{5}$ J. P. Boeuf, Y. Lagmich, T. Unfer, T. Callegari, and L. C. Pitchford, J. Phys. D: Appl. Phys. 40, 652 (2007).

${ }^{6}$ S. Hofmann, A. Sobota, and P. Bruggeman, IEEE Trans Plasma Sci. 40, 2888 (2012).

${ }^{7}$ S. Takamura, S. Saito, G. Kushida, M. Kando, and N. Ohno, IEEJ Trans. Fundam. Mater. 130, 493 (2010).

${ }^{8}$ E. A. D. Carbone, J. M. Palomares, S. Hübner, E. Iordanova, and J. J. A. M. van der Mullen, J. Instrum. 7, C01016 (2012).

${ }^{9}$ S. Ashida, C. Lee, and M. A. Lieberman, J. Vac. Sci. Technol. 13, 2498 (1995).

${ }^{10}$ N. Balcon, A. Aanesland, and R. Boswell, Plasma Sources Sci. Technol. 16, 217 (2007).

${ }^{11}$ X. M. Zhu, Y. K. Pu, N. Balcon, and R. Boswell, J. Phys. D 42, 142003 (2009).

${ }^{12}$ J. Schäfer, F. Sigeneger, R. Foest, D. Loffhagen, and K.-D. Weltmann, Eur. Phys. J. D 60, 531 (2010).

${ }^{13}$ M. Moravej, X. Yang, G. R. Nowling, J. P. Chang, R. F. Hicks, and S. E. Babayan, J. Appl. Phys. 96, 7011 (2004).

${ }^{14}$ S. G. Belostotskiy, R. Khandelwal, Q. Wang, V. M. Donnelly, D. J. Economou, and N. Sadeghi, Appl. Phys. Lett. 92, 221507 (2008).

${ }^{15}$ M. A. Lieberman and A. J. Lichtenberg, Principles of Plasma Discharges and Materials Processing, 2nd ed. (John Wiley \& Sons, Inc., Hoboken, New Jersey, 2005).

${ }^{16}$ G. Park, H. Lee, G. Kim, and J. K. Lee, Plasma Processes Polym. 5, 569 (2008). 